\title{
Effect of Hepatitis C Treatment with Ombitasvir/ Paritaprevir/R + Dasabuvir on Renal, Cardiovascular and Metabolic Extrahepatic Manifestations: A Post- Hoc Analysis of Phase 3 Clinical Trials
}

\author{
Darshan A. Mehta (D) Eric Cohen - Mariem Charafeddine - Daniel E. Cohen • \\ Yanjun Bao · Yuri Sanchez Gonzalez • Tram T. Tran
}

Received: July 25, 2017 / Published online: September 22, 2017

(C) The Author(s) 2017. This article is an open access publication

\section{ABSTRACT}

Introduction: We analyzed phase 3 trial data of ombitasvir/paritaprevir/ritonavir and dasabuvir (3D) \pm ribavirin (RBV) in genotype 1 chronic hepatitis $C$ patients to investigate the impact of $3 \mathrm{D} \pm \mathrm{RBV}$ on renal, cardiovascular and metabolic extrahepatic manifestations (EHMs), including persistency 52 weeks post treatment and differential impact by EHM disease severity. Methods: Estimated glomerular filtration rate (eGFR), fasting triglyceride and fasting glucose

Enhanced content To view enhanced content for this article go to http://www.medengine.com/Redeem/ EDFBF0607903C520.

Electronic supplementary material The online version of this article (doi:10.1007/s40121-017-0171-0) contains supplementary material, which is available to authorized users.

D. A. Mehta

Schaeffer Center for Health Policy and Economics, University of Southern California, Los Angeles, CA, USA

D. A. Mehta $(\bowtie) \cdot$ Y. Bao · Y. Sanchez Gonzalez Health Economics and Outcomes Research, AbbVie Inc., Mettawa, IL, USA

e-mail: darshan.mehta@abbvie.com

E. Cohen · M. Charafeddine $\cdot$ D. E. Cohen Infectious Disease Development, AbbVie Inc., Mettawa, IL, USA

T. T. Tran

Cedars-Sinai Medical Center, Los Angeles, CA, USA values from clinical trials were used to assess renal, cardiovascular and metabolic EHMs, respectively. Two placebo-controlled trials were used to study the effect of treatment, while the pooled sample of treated patients was used to study the persistency and differential effect of treatment by baseline EHM disease severity, as defined by baseline values of respective EHM biomarkers. Changes in EHM outcomes from baseline were assessed with mixed models adjusting for patient baseline demographic and clinical characteristics.

Results: Treatment with $3 \mathrm{D} \pm \mathrm{RBV}$ resulted in statistically significant declines from baseline of triglycerides and glucose and no statistical change in eGFR. By 52 weeks post treatment patients with elevated triglycerides $(-35.3 \mathrm{mg} /$ $\mathrm{dl})$, pre-diabetes $(-4.4 \mathrm{mg} / \mathrm{dl})$, diabetes $(-34.2 \mathrm{mg} / \mathrm{dl})$ and CKD stage $3(+1.6 \mathrm{ml} / \mathrm{min} /$ $1.73 \mathrm{~m}^{2}$ ) at baseline experienced a statistically significant improvement in their respective EHM values. Patients with CKD stages 2, 4 and 5 experienced no statistically significant change in eGFR from baseline.

Conclusion: Treatment with $3 \mathrm{D} \pm \mathrm{RBV}$ resulted in improvement or no worsening of cardiovascular, metabolic and renal EHM markers, especially in patients with severe EHMs at baseline, which persisted until 52 weeks post treatment.

Funding: Abbvie Inc.

Keywords: Dasabuvir; Extrahepatic manifestations; eGFR; Glucose; Hepatitis c; 
Ombitasvir; Paritaprevir; Placebo; Ritonavir; Triglycerides

\section{INTRODUCTION}

Most recent estimates suggest that between 2.5 and 4.7 million people are currently living with chronic hepatitis $\mathrm{C}$ virus infection $(\mathrm{HCV})$ in the USA [1]. Patients with HCV are at increased risk of long-term liver complications, including cirrhosis, hepatocellular carcinoma, liver failure, and liver-related mortality [2]. In addition, HCV is also associated with a number of extrahepatic manifestations (EHMs) including type 2 diabetes mellitus, insulin resistance, cardiovascular disease, mixed cryoglobulinemia, chronic kidney disease (CKD), non-Hodgkin's lymphoma and cognitive impairment [3-9]. Evidence suggests that while up to $74 \%$ of HCV-infected patients may have at least one EHM, these risks are typically not accounted or underappreciated by treaters. [4].

Several empirical studies have shown that sustained virologic response (SVR) with antiviral therapy is associated with reduced risk of hepatic complications [10-12], but few studies have evaluated the impact of SVR with HCV treatment on EHM outcomes. One study found that $\mathrm{HIV} / \mathrm{HCV}$ co-infected individuals not responding to interferon (IFN)-based regimens had increased odds of non-liver and non-AIDS-related death [hazard ratio (HR): 2.85; $p=0.036$ ] [13]. In a nationwide Taiwanese cohort of HCV patients, peg-IFN/RBV antiviral treatment was associated with lower odds of adverse extrahepatic outcomes (i.e., end-stage renal disease, acute coronary syndrome and ischemic stroke) $[14,15]$.

The standard of care for HCV patients now comprises IFN-free therapy with direct-acting antiviral agents (DAAs) that have shorter durations, higher efficacy and an improved safety profile [16]. However, the impact of DAAs on EHMs and the persistence of this effect post treatment are not well defined. Also, it is not known whether pre-treatment severity of EHMs, based on baseline biomarker values, affects the impact of DAAs. To address these evidence gaps, we leveraged clinical trial data of ombitasvir/paritaprevir/ritonavir (paritaprevir identified by AbbVie and Enanta) and dasabuvir \pm ribavirin $(3 \mathrm{D} \pm \mathrm{RBV})$ for treatment of $\mathrm{HCV}$ genotype 1-infected patients to study:

1 . the impact of $3 \mathrm{D} \pm \mathrm{RBV}$ on renal, cardiovascular and metabolic EHMs;

2. the persistency of any treatment impact on EHMs 52 weeks post treatment;

3. the differential impact of treatment by EHM disease severity.

\section{METHODS}

For this analysis, EHMs were defined as non-liver-related conditions that have been associated with HCV infection [17]. The current study incorporated fasting triglycerides, fasting glucose and estimated glomerular filtration rate (eGFR) as surrogate measures of cardiovascular, metabolic and renal EHMs, respectively. These biomarker levels have been associated with varying risk of clinical outcomes [18-22]. The data were extracted from two pivotal placebo-controlled phase 3 trials (SAPPHIRE I [23] and II [24]) and two long-term phase 3b trials (TOPAZ I [25] and II [26]). Furthermore, two phase $3 \mathrm{~b}$ trials (RUBY I [27] and II [28]) were used to study the impact of treatment on renal EHMs in patients with advanced renal impairment at baseline (i.e., CKD stages 4 and 5). Appendix Table $S 1$ provides a brief overview of the clinical trials. This analysis was conducted based on biomarker data collected in previously conducted studies and did not involve any new studies of human or animal subjects performed by any of the authors.

For cardiovascular and metabolic manifestations, only those patients whose baseline triglyceride and glucose samples were collected in a fasting state were included in the analysis. Subsequent values not collected in a fasting state were treated as missing. No such restrictions were applied to the collection of eGFR values since they are independent of fasting state, so all patients with available eGFR values at baseline were included in the analysis.

Table 1 provides a summary of the patient populations and clinical trials used for each study objective. The effect of $3 \mathrm{D} \pm \mathrm{RBV}$ on $\mathrm{EHM}$ 
Table 1 Study populations and data sources

\begin{tabular}{|c|c|c|c|}
\hline $\begin{array}{l}\text { Study } \\
\text { population }\end{array}$ & Description & Study period & Study objective \\
\hline \multirow[t]{2}{*}{ SP1 } & $\begin{array}{l}\text { Patients from two placebo-controlled phase } 3 \mathrm{a} \\
\text { trials (SAPPHIRE I and II) who received } \\
12 \text { weeks of 3D + RBV }\end{array}$ & 12-week DB period & $\begin{array}{c}\text { Effect of HCV treatment on EHM } \\
\text { outcomes (see Figs. 1a, 2a, 3a) }\end{array}$ \\
\hline & $\begin{array}{l}\text { Patients from two placebo controlled phase } 3 \text { a } \\
\text { trials (SAPPHIRE I and II) who received } \\
12 \text { weeks of placebo during the DB period } \\
\text { followed by } 12 \text { weeks of } 3 \mathrm{D}+\mathrm{RBV} \text { during } \\
\text { the OL period }\end{array}$ & & \\
\hline SP2 & $\begin{array}{l}\text { Patients who received } 12 \text { or } 24 \text { weeks of } \\
3 \mathrm{D} \pm \mathrm{RBV} \text { across } 2 \text { long-term phase } 3 \mathrm{~b} \\
\text { trials (TOPAZ I and II) }\end{array}$ & $\begin{array}{l}\text { 12/24-week } \\
\text { treatment period } \\
\text { followed for } \\
52 \text { weeks PT }\end{array}$ & $\begin{array}{l}\text { Differential effect of HCV treatment } \\
\text { by EHM severity and persistency } \\
\text { PT (see Figs. 1b, 2b, 3b) }\end{array}$ \\
\hline SP3 & $\begin{array}{l}\text { Patients with CKD stage } 4 \text { or } 5 \text { who received } \\
12 \text { or } 24 \text { weeks of } 3 D \pm R B V \text { across } 2 \text { phase } \\
3 b \text { trials (RUBY I and II) }\end{array}$ & $\begin{array}{l}\text { 12/24 week } \\
\text { treatment period } \\
\text { followed for } \\
12 \text { weeks PT }\end{array}$ & $\begin{array}{l}\text { Differential effect of HCV treatment } \\
\text { by EHM severity and persistency } \\
\text { PT (see Fig. 3c) }\end{array}$ \\
\hline
\end{tabular}

All patients in trials were GT1 patients

$S P$ study population, $P T$ post treatment, $D B$ double blind, $O L$ open label, $E H M$ extra-hepatic manifestation, $C K D$ chronic kidney disease, $R B V$ ribavirin, $3 D$ ombitasvir/paritaprevir/ritonavir + dasabuvir

outcome was assessed by comparing the treatment and placebo arm of SAPPHIRE trials using the 12-week double-blind treatment period. For both treatment and placebo arms, mean change from baseline to end of treatment (EOT) was assessed. Statistical significance for these mean changes was evaluated using the $t$ test. Longitudinal mixed model (MM) regressions [29] were used to assess the treatment effect on each EHM biomarker. The MM regression controlled for patient baseline biomarker values, demographics and clinical characteristics (i.e., fibrosis stage, genotype, age, gender, BMI, presence of diabetes, HCV treatment history, viral load). In addition, since we pooled data from two trials, the model also controlled for clinical trial enrollment of patients. Due to serial measurements, the model assumed a first order autoregressive covariance structure. The change from baseline to subsequent time points was estimated and plotted based on the regression coefficients from the MM.
Data on the treated population in TOPAZ trials were used to study the effect of $\mathrm{HCV}$ treatment by baseline EHM severity and persistency of this effect 52 weeks post treatment. For cardiovascular EHMs, patients with fasting baseline triglycerides greater than or equal to $150 \mathrm{mg} / \mathrm{dl}$ were defined as elevated [30]. For metabolic EHMs, patients with fasting baseline glucose values between 100 and $126 \mathrm{mg} / \mathrm{dl}$ were defined as having pre-diabetes and those with fasting baseline glucose higher than $126 \mathrm{mg} / \mathrm{dl}$ were defined as having diabetes [31], irrespective of any reported history of diabetes. For renal EHMs, CKD stages were defined based on Kidney Disease Improving Global Outcomes (KDIGO) guidelines as stage 1 (eGFR $\geq 90 \mathrm{ml} /$ $\mathrm{min} / 1.73 \mathrm{~m}^{2}$ ), stage 2 (eGFR $60-89 \mathrm{ml} / \mathrm{min} /$ $\left.1.73 \mathrm{~m}^{2}\right)$, stage $3\left(30-59 \mathrm{ml} / \mathrm{min} / 1.73 \mathrm{~m}^{2}\right)$, stage 4 (eGFR $15-29 \mathrm{ml} / \mathrm{min} / 1.73 \mathrm{~m}^{2}$ ) or stage 5 (eGFR $<15 \mathrm{ml} / \mathrm{min} / 1.73 \mathrm{~m}^{2}$ or dialysis dependent) [32]. Mean change from baseline was assessed at EOT, post-treatment week 12 and 52. In 
addition, we assessed the proportion of patients with biomarker value improvements less than, equal to or greater than $20 \%$ for each EHM severity group at EOT, post-treatment week 12 and 52. Improvement in cardiovascular and metabolic EHMs was defined as a decrease in the triglycerides and glucose values, respectively, and improvement in renal EHM was defined as an increase in eGFR. As before, MM regressions were used to estimate the persistency and differential impact of 3D \pm RBV on EHM outcomes by disease severity, controlling for patient baseline values, demographics, clinical characteristics and clinical trial enrollment.

\section{RESULTS}

\section{Patient Demographics and Descriptive Analyses}

Table 2 presents the baseline characteristics of the study population. Across the different clinical trials, the mean age of the population was $51(50.1-57.7)$ years, with at least 69\% (69-91\%) of the population being in the F0-F2 fibrosis stages. With respect to clinical profile, at least $66 \%(66-83 \%)$ and $58 \%(58-74 \%)$ of the study population had BMI $<30 \mathrm{~kg} / \mathrm{m}^{2}$ and HOMA-IR $<3 \mathrm{mU} \mathrm{mmol} / \mathrm{l}^{2}$, respectively. There was fairly even distribution across sub-genotype $1 \mathrm{a}$ and $1 \mathrm{~b}$ and at least $55 \%(55-82 \%)$ of patients were treatment naïve. SVR rates across the study population were greater than 95\% (95-97.6\%). Appendix Table S2 presents baseline characteristics of the patients by baseline EHM disease severity.

Descriptive analysis of the proportion of patients experiencing improvements showed across EHMs a greater proportion of patients who had severe EHM manifestations at baseline improved by greater than $20 \%$ from baseline (Table 3). These effects were sustained at all time points.

Regression analyses on cardiovascular EHMs show a significant reduction in mean triglyceride levels 12 weeks EOT with $3 \mathrm{D} \pm \mathrm{RBV}$ vs. placebo. The mean adjusted change from baseline to EOT week 12 for treated patients was $-33.7 \mathrm{mg} / \mathrm{dl} \quad(p<0.0001 ; \quad 95 \% \quad$ CI -41.1 ,
$26.5 \mathrm{mg} / \mathrm{dl}$ ), while patients in the placebo group did not have statistically significant changes $(-5.6 \mathrm{mg} / \mathrm{dl}$ at week $12 ; p=0.53 ; 95 \% \mathrm{CI}-23.5$, $12.2 \mathrm{mg} / \mathrm{dl}$ ) (Fig. 1a). Patients with elevated levels of triglycerides at baseline experienced greater declines in triglycerides during treatment compared to patients with normal triglycerides. Moreover, this difference persisted 52 weeks post treatment (Fig. 1b): patients with elevated triglycerides experienced a decline of $35.3 \mathrm{mg} / \mathrm{dl}(p<0.001 ; 95 \% \mathrm{CI}-48.2,-22.3 \mathrm{mg} /$ $\mathrm{dl})$, and patients with normal triglycerides had an increase of $16.2 \mathrm{mg} / \mathrm{dl}$ ( $p<0.001 ; 95 \%$ CI 11 , $21.4 \mathrm{mg} / \mathrm{dl}$ ), which did not result in levels over $150 \mathrm{mg} / \mathrm{dl}$.

Treatment with $3 \mathrm{D} \pm \mathrm{RBV}$ also significantly improved metabolic EHMs, as the adjusted mean glucose levels 12 weeks EOT were significantly lower in patients treated with $3 \mathrm{D} \pm \mathrm{RBV}$ vs. placebo [mean adjusted change of $-12.1 \mathrm{mg} / \mathrm{dl}(p<0.0001)$ for treated patients vs. $-4.6 \mathrm{mg} / \mathrm{dl}(p=0.02)$ for the placebo group; Fig. 2a]. Among the EHM subgroups, patients with pre-diabetes and diabetes experienced greater reduction in glucose levels during treatment (Fig. 2b) compared to patients with normal glucose levels. This difference persisted 52 weeks post treatment. Patients with pre-diabetes and diabetes experienced a decline of $4.4 \mathrm{mg} / \mathrm{dl}(p=0.004 ; 95 \% \mathrm{CI}-7.3,-1.4 \mathrm{mg} / \mathrm{dl})$ and $34.2 \mathrm{mg} / \mathrm{dl} \quad(p<0.0001 ; 95 \%$ CI -39.4 , $-28.9 \mathrm{mg} / \mathrm{dl})$, respectively, and patients with normal glucose had a statistically insignificant increase of $1.9 \mathrm{mg} / \mathrm{dl}$ ( $p=0.062 ; 95 \% \mathrm{CI}-0.09$, $3.85 \mathrm{mg} / \mathrm{dl}$ ), which did not result in levels over $100 \mathrm{mg} / \mathrm{dl}$ (Fig. 2b).

Renal EHMs were not significantly affected after 12 weeks of treatment with $3 \mathrm{D} \pm \mathrm{RBV}$ vs. placebo as both groups had no statistically significant changes in eGFR values from baseline [mean adjusted change of $+0.37 \mathrm{ml} / \mathrm{min} /$ $1.73 \mathrm{~m}^{2} \quad(p=0.82)$ for patients treated with $3 \mathrm{D} \pm \mathrm{RBV}$ vs. $+3.48 \mathrm{ml} / \mathrm{min} / 1.73 \mathrm{~m}^{2}(p=0.19)$ for patients in placebo arm] (Fig. 3a). However, the subgroup of patients with CKD stage 2 and 3 experienced minor to significant improvements in eGFR during treatment (Fig. 3b) compared to patients with normal eGFR values, respectively. By 52 weeks post treatment, stage 3 patients experienced an improvement of $1.6 \mathrm{ml} / \mathrm{min} /$ 
Table 2 Baseline characteristics of study population

\begin{tabular}{|c|c|c|c|c|c|c|c|}
\hline & \multicolumn{3}{|c|}{$\mathrm{CV}$ and metabolic } & \multicolumn{4}{|l|}{ Renal } \\
\hline & \multicolumn{2}{|c|}{$\begin{array}{l}\text { Phase 3a studies } \\
\text { (SAPPHIRE I and } \\
\text { II) }\end{array}$} & \multirow{2}{*}{$\begin{array}{l}\text { Phase 3b: } \\
\text { TOPAZ studies } \\
\text { SP2, all treated }\end{array}$} & \multicolumn{2}{|c|}{$\begin{array}{l}\text { Phase 3a studies } \\
\text { (SAPPHIRE I and } \\
\text { II) }\end{array}$} & \multirow{2}{*}{$\begin{array}{l}\text { Phase 3b: } \\
\text { TOPAZ } \\
\text { studies } \\
\text { SP2, all treated }\end{array}$} & \multirow{2}{*}{$\begin{array}{l}\text { Phase 3b: } \\
\text { RUBY studies } \\
\text { SP3 all treated }\end{array}$} \\
\hline & $\begin{array}{l}\text { SP1, } \\
\text { treatment }\end{array}$ & $\begin{array}{l}\text { SP1, } \\
\text { placebo }\end{array}$ & & $\begin{array}{l}\text { SP1, } \\
\text { treatment }\end{array}$ & $\begin{array}{l}\text { SP1, } \\
\text { placebo }\end{array}$ & & \\
\hline$N$ & 630 & 199 & 1845 & 776 & 255 & 2206 & 82 \\
\hline Age (years, mean) & 50.1 & 52.1 & 51.8 & 50.3 & 52.6 & 52.1 & 57.7 \\
\hline \multicolumn{8}{|l|}{ Gender } \\
\hline Male (\%) & 56.0 & 52.3 & 53.0 & 57.2 & 52.2 & 53.0 & 80.5 \\
\hline Female (\%) & 44.0 & 47.7 & 47.0 & 42.8 & 47.8 & 47.3 & 19.5 \\
\hline \multicolumn{8}{|l|}{ Race } \\
\hline White (\%) & 90.6 & 90.5 & 93.4 & 90.7 & 90.6 & 93.6 & 45.1 \\
\hline Black (\%) & 6.3 & 6.5 & 4.2 & 6.4 & 7.1 & 6.7 & 54.9 \\
\hline Asian (\%) & 2.4 & 1.5 & 0.0 & 2.2 & 1.2 & 0.0 & 6.1 \\
\hline Others (\%) & 0.6 & 1.5 & 0.2 & 0.6 & 1.2 & 0.0 & 4.9 \\
\hline \multicolumn{8}{|l|}{ Region/countries } \\
\hline North America (\%) & 47.0 & 38.7 & 25.8 & 47.6 & 42.0 & 27.9 & 100.0 \\
\hline $\begin{array}{l}\text { Australia/New } \\
\text { Zealand/other (\%) }\end{array}$ & 4.9 & 6.0 & 58.8 & 5.7 & 6.7 & 59.2 & 0.0 \\
\hline Europe (\%) & 48.1 & 55.3 & 15.4 & 46.8 & 51.4 & 13.1 & 0.0 \\
\hline \multicolumn{8}{|l|}{ Fibrosis } \\
\hline F0-F1 (\%) & 74.9 & 72.9 & 55.9 & 73.1 & 71.0 & 56.6 & 41.5 \\
\hline F2 (\%) & 15.7 & 16.1 & 13.2 & 16.1 & 17.3 & 13.4 & 28.0 \\
\hline F3 (\%) & 9.4 & 11.1 & 15.1 & 10.8 & 11.8 & 14.3 & 12.2 \\
\hline F4 (\%) & 0.0 & 0.0 & 15.8 & 0.0 & 0.0 & 15.9 & 18.3 \\
\hline \multicolumn{8}{|l|}{ Sub-genotype } \\
\hline $1 \mathrm{~A}(\%)$ & 63.2 & 59.3 & 48.5 & 64.4 & 63.5 & 51.8 & 72.0 \\
\hline 1B (\%) & 36.8 & 40.7 & 51.2 & 35.6 & 36.5 & 48.1 & 22.0 \\
\hline Other (\%) & & & & & & & 6.1 \\
\hline \multicolumn{8}{|l|}{ Treatment arms } \\
\hline 3D 12 weeks (\%) & 0.0 & 0.0 & 43.3 & 0.0 & 0.0 & 40.8 & 40.2 \\
\hline $\begin{array}{l}3 \mathrm{D}+\mathrm{RBV} \\
12 \text { weeks (\%) }\end{array}$ & 100.0 & 0.0 & 50.0 & 100.0 & 0.0 & 52.4 & 50.0 \\
\hline
\end{tabular}


Table 2 continued

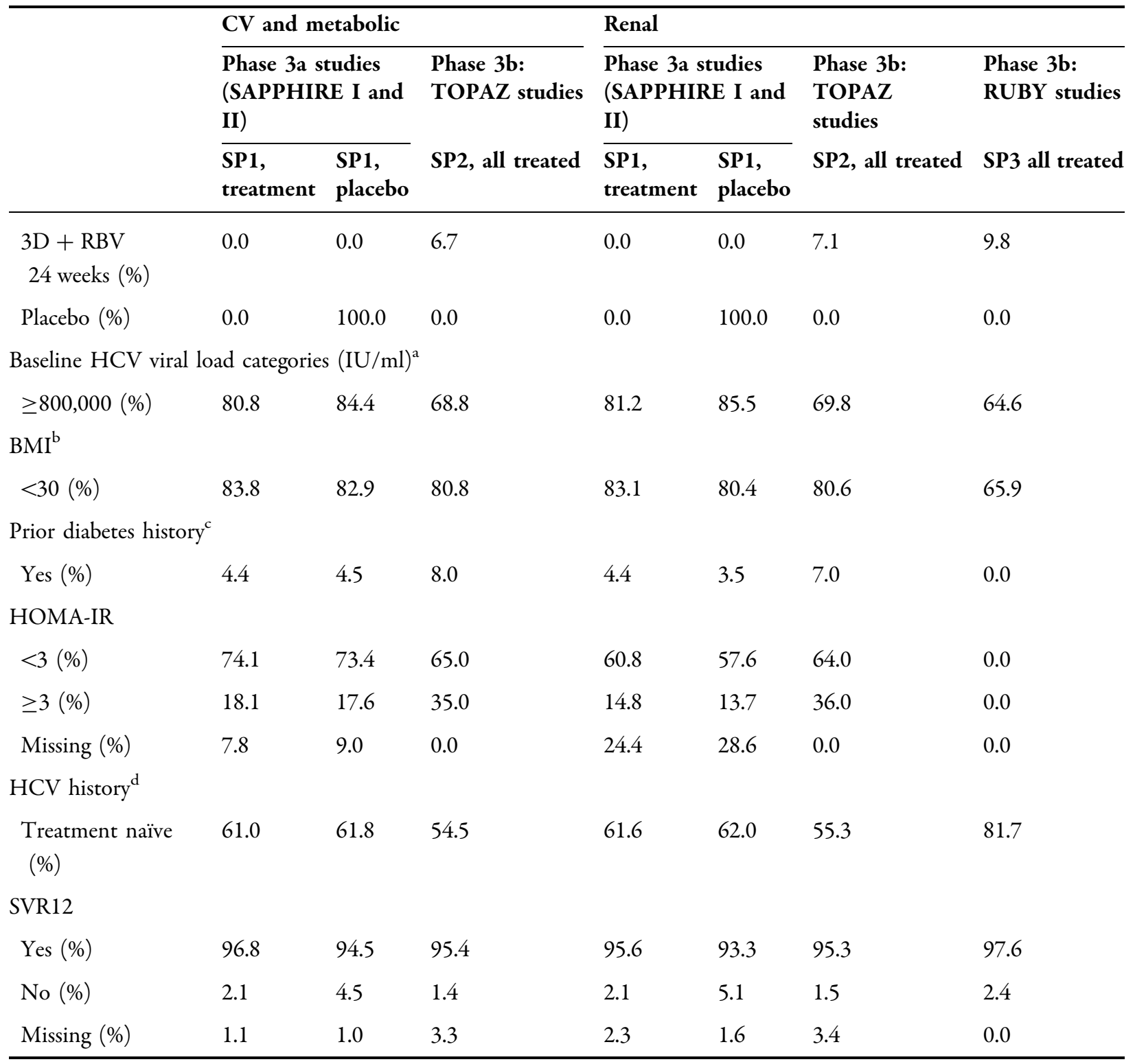

$B M I$ body mass index

a Rest of the proportion represents patients with baseline viral load less than $800,000 \mathrm{IU} / \mathrm{ml}$

b Rest of the proportion represents patients with $\mathrm{BMI} \geq 30$

c Rest of the proportion represent patients with no diabetes

$\mathrm{d}$ Rest of the proportion represents patients who are experienced with an interferon-based regimen. All patients in trials were GT1 patients. HOMA-IR: Homeostatic model assessment: insulin resistance

$1.73 \mathrm{~m}^{2} \quad(p=0.7 ; 95 \%$ CI $-6.6,9.9 \mathrm{ml} / \mathrm{min} /$ $1.73 \mathrm{~m}^{2}$ ). Stage 2 patients experienced a statistically insignificant decline of $2.2 \mathrm{ml} / \mathrm{min} /$ $1.73 \mathrm{~m}^{2}(p=0.13 ; 95 \% \mathrm{CI}-4.9,0.6)$. Stage 1 patients experienced a decrement of $9.3 \mathrm{ml} /$ $\min / 1.73 \mathrm{~m}^{2} \quad(p<0.001 ; 95 \%$ CI -10.8 ,
$-7.8 \mathrm{ml} / \mathrm{min} / 1.73 \mathrm{~m}^{2}$ ) (Fig. 3b). The CKD stage 4 and 5 patients experienced no statistically significant decrements during treatment and returned to baseline values by week 12 post treatment (Fig. 3c). Stage 4: $-0.81 \mathrm{ml} / \mathrm{min} /$ $1.73 \mathrm{~m}^{2} ; p=0.53 ; 95 \% \mathrm{CI}-3.4,1.7 \mathrm{ml} / \mathrm{min} /$ 
Table 3 Proportion of treated population improving from baseline value at specific time points

\begin{tabular}{|c|c|c|c|c|c|c|}
\hline & \multicolumn{3}{|c|}{$\leq 20 \%$ Improvement } & \multicolumn{3}{|c|}{$>20 \%$ Improvement } \\
\hline & EOT (\%) & PTW 12 (\%) & PTW52 (\%) & EOT (\%) & PTW12 (\%) & PTW52 (\%) \\
\hline \multicolumn{7}{|l|}{ Triglycerides } \\
\hline Normal & 21 & 22.7 & 22.1 & 13.8 & 13.5 & 15.4 \\
\hline Elevated & 17.8 & 17.7 & 13.5 & 54 & 48.3 & 50.4 \\
\hline \multicolumn{7}{|l|}{ Glucose } \\
\hline Normal & 32.5 & 24.7 & 32.1 & 16.8 & 32.4 & 18.2 \\
\hline Pre-diabetic & 49 & 43 & 46.3 & 21.4 & 37.1 & 21.7 \\
\hline Diabetic & 34.3 & 30.6 & 42.9 & 46.2 & 51.9 & 45.5 \\
\hline \multicolumn{7}{|l|}{$e G F R^{a}$} \\
\hline Stage 1 & 32.2 & 29.4 & 19.7 & 2.4 & 2.3 & 2.2 \\
\hline Stage 2 & 38.1 & 35.3 & 20.4 & 6.2 & 6.4 & 4.8 \\
\hline Stage 3 & 33.3 & 31.5 & 16 & 10.4 & 7.4 & 8 \\
\hline Stage $4^{\wedge}$ & 40.4 & 30.8 & - & 6.7 & 15.4 & - \\
\hline Stage $5^{\wedge}$ & 41.4 & 33.3 & - & 24.1 & 11.9 & - \\
\hline
\end{tabular}

Results based on patients enrolled in long-term TOPAZ trials. ${ }^{\wedge}$ Results for stage 4, 5 CKD patients based on patients enrolled in RUBY trials

Fasting baseline TGL greater than or equal to $150 \mathrm{mg} / \mathrm{dl}$ was defined as elevated. Patients with a fasting baseline glucose value between 100 and $126 \mathrm{mg} / \mathrm{dl}$ were defined as pre-diabetic and with glucose higher than $126 \mathrm{mg} / \mathrm{dl}$ were defined as diabetic. Chronic kidney disease stages were defined based on guidelines as stage 1 [signs of kidney damage but normal or elevated (eGFR $\geq 90$ )], stage 2 (eGFR 60-89), stage 3 (30-59), stage 4 (eGFR 15-29) or stage 5 (eGFR $<15$ or dialysis dependent)

EOT end of treatment, PTW12 post-treatment week 12, PTW52 post-treatment week 52, TGL triglycerides, GLC glucose, eGFR estimated glomerular filtration rate

a For eGFR improvement was defined as an increase in eGFR from baseline to a defined time point. For TGL and glucose, improvement was defined as a reduction in biomarker from baseline to a defined time point. All patients in trials were GT1 patients

$1.73 \mathrm{~m}^{2}$. Stage $5: 0.09 \mathrm{ml} / \mathrm{min} / 1.73 \mathrm{~m}^{2} ; p=0.9$; $95 \% \mathrm{CI}-1.25,1.43 \mathrm{ml} / \mathrm{min} / 1.73 \mathrm{~m}^{2}$.

Unadjusted analysis is presented in appendix Table S3 for the three EHMs and is consistent with the adjusted results presented.

\section{DISCUSSION}

The results from this analysis suggest that treatment with $3 \mathrm{D} \pm \mathrm{RBV}$ was associated with improvements in EHM biomarkers for cardiovascular, metabolic and renal EHMs. These results are consistent with the beneficial effect observed in patients treated with interferon-based regimens [14, 15, 33]. Furthermore, the beneficial effect of treatment was most pronounced in individuals with more severe markers of EHMs, and EHM improvements were sustained at least 1 year post treatment.

\section{Cardiovascular EHMs}

The mean decrement of triglycerides in treated patients at 52 weeks post treatment was $9.5 \mathrm{mg} /$ dl overall and $35.2 \mathrm{mg} / \mathrm{dl}$ for patients with elevated triglycerides at baseline. The magnitude 

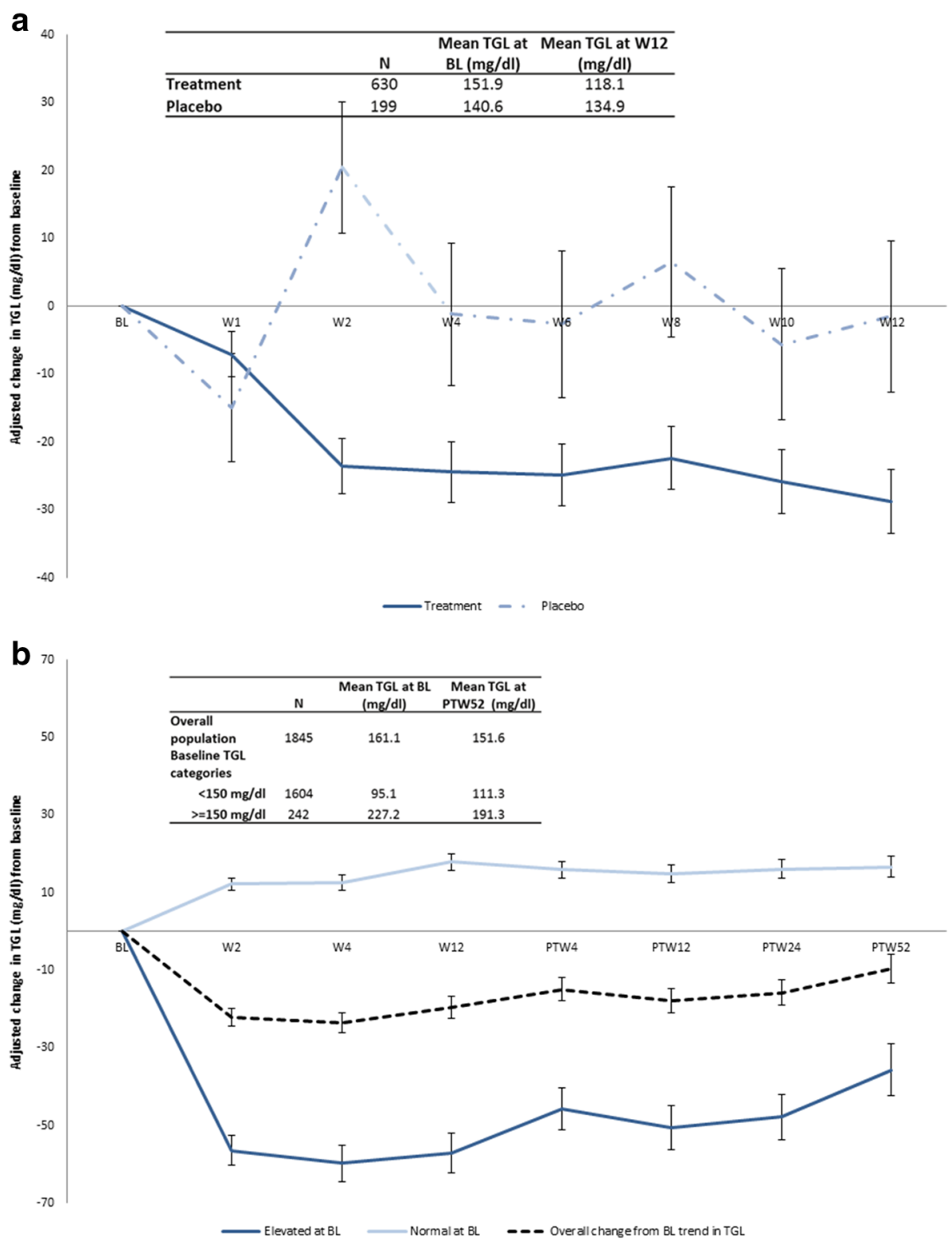

Fig. 1 a Predicted change in triglycerides from baseline: comparison of HCV-treated and placebo arms. Study conducted on treatment and placebo arms of SP1 [i.e., patients from placebo controlled phase 3a trials (SAPPHIRE I and II)]. All patients in trials were GT1 patients. The graphs depict predicted change from baseline at individual time points based on longitudinal mixed model regression. The model regressed value of triglycerides at each time point on whether patients were in HCV-treated or placebo group and adjusted for baseline triglyceride level, fibrosis stages, genotype, age, BMI, presence of diabetes, treatment history, viral load and study enrollment. Error bars represent standard errors. $T G L$ triglycerides, $B L$ baseline, $W$ week. b Predicted triglyceride change from baseline until post-treatment week 52 among treated patients by baseline triglyceride levels. Fasting baseline TGLs greater than or equal to $150 \mathrm{mg} / \mathrm{dl}$ were defined as elevated TGLs. Study conducted on SP3. SP3 comprises of all the HCV-treated population from long-term phase $3 \mathrm{~b}$ trials (TOPAZ I and II). All patients in trials were GT1 patients. The graphs depict predicted change from baseline at individual time points based on longitudinal mixed model regression. The model regressed longitudinal triglyceride value on baseline triglyceride level categories and adjusted for fibrosis stages, genotype, age, BMI, presence of diabetes, treatment history, viral load and study enrollment. Error bars represent standard errors. $T G L$ triglycerides, $B L$ baseline, $W$ week, $P T W$ post-treatment week 


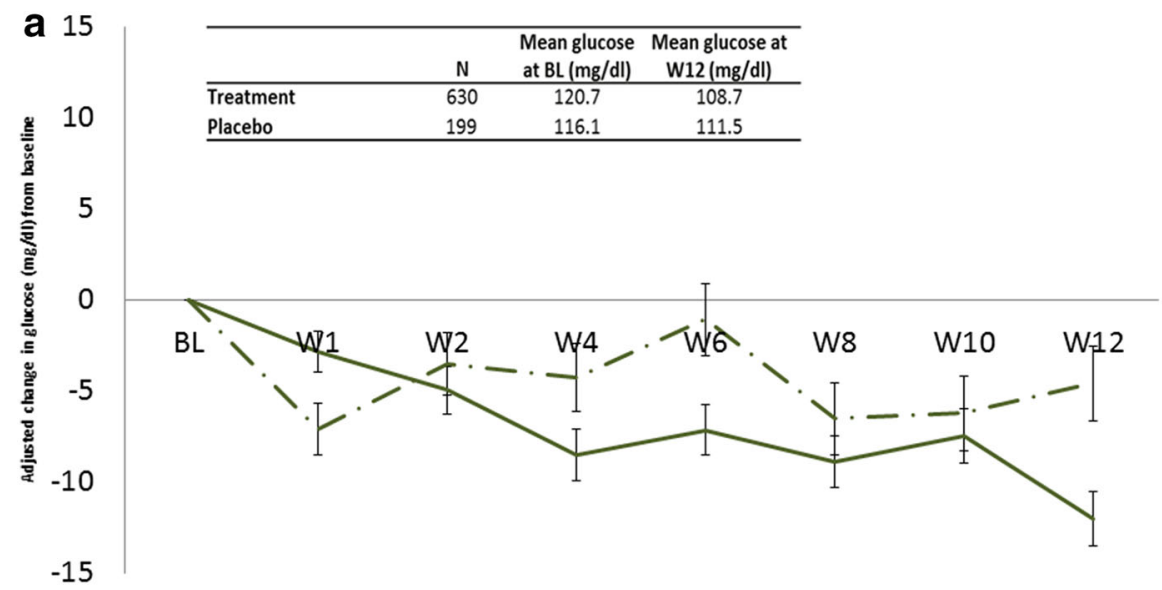

Treatment $\longrightarrow$ Placebo

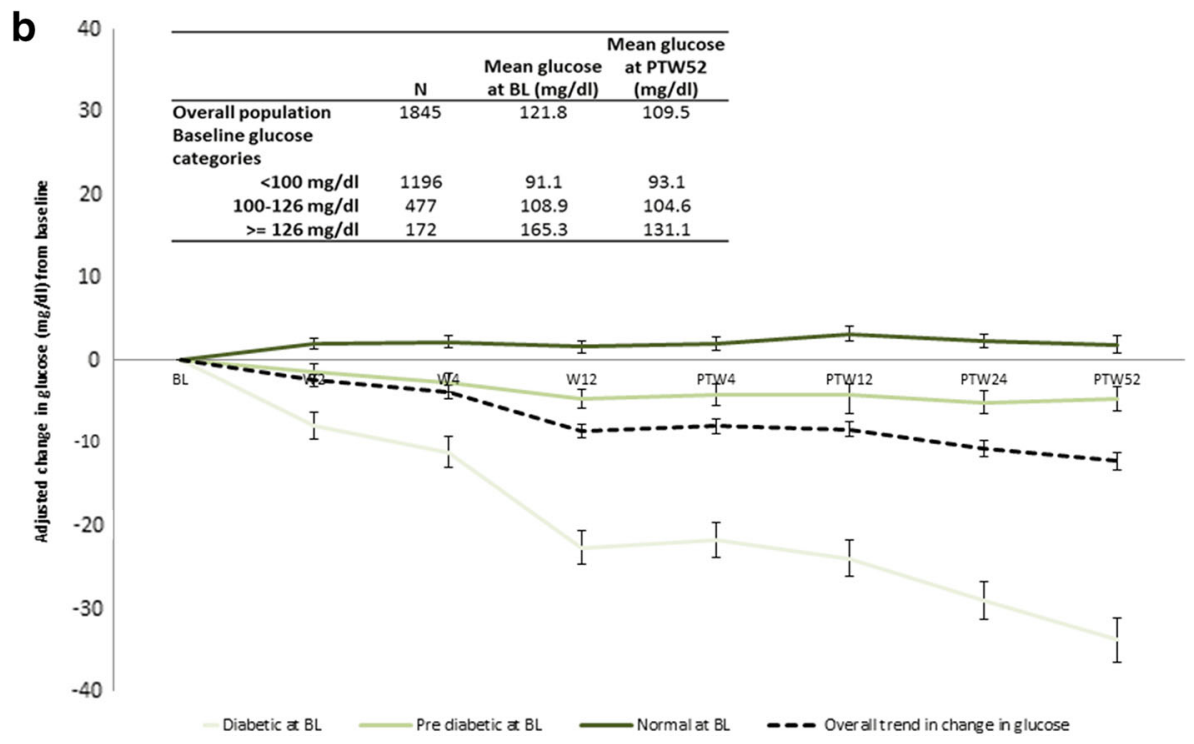

Fig. 2 a Predicted change in glucose from baseline: comparison of HCV-treated and placebo arms. Study conducted on treatment and placebo arms of SP1 [i.e., patients from placebo controlled phase $3 a$ trials (SAPPHIRE I and II)]. All patients in trials were GT1 patients. The graphs depict predicted change from baseline at individual time points based on longitudinal mixed model regression. The model regressed value of glucose at each time point on whether patients were in the HCV-treated or placebo group and adjusted for baseline glucose level, fibrosis stages, genotype, age, BMI, presence of diabetes, treatment history, viral load and study enrollment. Error bars represent standard errors. $B L$ baseline, $W$ week. b Predicted glucose change from baseline until post-treatment week 52 among treated patients by baseline glucose levels. Patients with fasting baseline glucose value between 100 and $126 \mathrm{mg} / \mathrm{dl}$ were defined as pre-diabetic and glucose higher than $126 \mathrm{mg} / \mathrm{dl}$ were defined as diabetic. Study conducted on SP3. SP3 comprises all of the $\mathrm{HCV}$-treated population from long-term phase $3 \mathrm{~b}$ trials (TOPAZ I and II). All patients in trials were GT1 patients. The graphs depict predicted change from baseline at individual time points based on longitudinal mixed model regression. The model regressed longitudinal glucose value on baseline glucose level categories and adjusted for fibrosis stages, genotype, age, BMI, presence of diabetes, treatment history, viral load and study enrollment. Error bars represent standard errors. $B L$ baseline, $W$ week, $P T W$ post-treatment week 


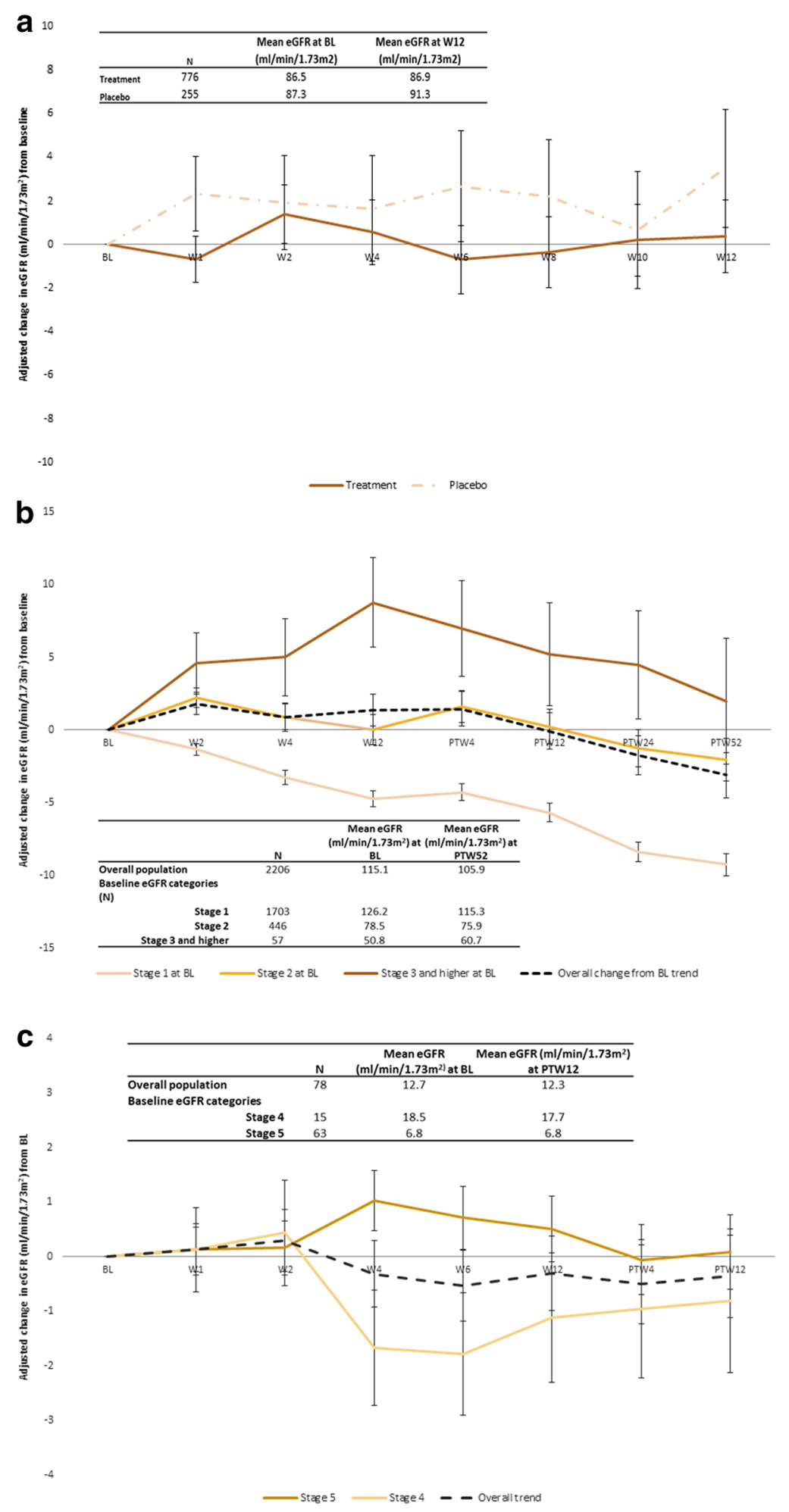


4Fig. 3 a Predicted change in eGFR from baseline: comparison of HCV-treated and placebo arms. Study conducted on treatment and placebo arms of SP1 [i.e., patients from placebo controlled phase 3a trials (SAPPHIRE I and II)]. All patients in trials were GT1 patients. The graphs depict predicted change from baseline at individual time points based on longitudinal mixed model regression. The model regressed values of eGFR at each time point on whether patients were in the HCV-treated or placebo group and adjusted for baseline eGFR level, fibrosis stages, genotype, age, BMI, presence of diabetes, treatment history, viral load and study enrollment. Error bars represent standard errors. $e G F R$ estimated glomerular filtration rate, $B L$ baseline, $W$ week. b Predicted eGFR change from baseline until post-treatment week 52 among treated patients by baseline eGFR levels. Chronic kidney disease stages were defined based on guidelines as stage 1 (signs of kidney damage but normal or elevated (eGFR $\geq 90$ ), stage 2 (eGFR 60-89), stage 3 (eGFR 30-59), stage 4 (eGFR 15-29) and stage 5 (eGFR $<15$ or dialysis dependent). Study conducted on SP2. SP2 comprises all of the HCV-treated population from long-term phase $3 \mathrm{~b}$ trials (TOPAZ I and II). All patients in trials were GT1 patients. The graphs depict predicted change from baseline at individual time points based on longitudinal mixed model regression. The model regressed longitudinal eGFR value on baseline eGFR level categories and adjusted for fibrosis stages, genotype, age, BMI, presence of diabetes, treatment history, viral load and study enrollment. Error bars represent standard errors. eGFR estimated glomerular filtration rate, $B L$ baseline, $W$ week, $P T W$ post-treatment week. c Predicted eGFR change from baseline until post-treatment week 12 among treated patients with CKD stage 4 or 5 at baseline. Chronic kidney disease stages were defined based on guidelines as stage 1 [signs of kidney damage but normal or elevated (eGFR $\geq 90)$ ], stage 2 (eGFR 60-89), stage 3 (eGFR 30-59), stage 4 (eGFR 15-29) or stage 5 (eGFR $<15$ or dialysis dependent). Study conducted on SP3. SP3 comprises all of the $\mathrm{HCV}$-treated population from renal-specific phase $3 \mathrm{~b}$ trials. All patients in trials were GT1 patients. The graphs depict predicted changes from baseline at individual time points based on longitudinal mixed model regression. The model regressed longitudinal eGFR value on baseline eGFR level categories and adjusted for fibrosis stages, genotype, age, BMI, presence of diabetes, treatment history, viral load and study enrollment. Error bars represent standard errors. $e G F R$ estimated glomerular filtration rate, $B L$ baseline, $W$ week, $P T W$ post-treatment week of these declines is comparable to the improvements observed in clinical trials of triglyceride-lowering drugs, which ranged from 8 to $50 \%$ [34]. Elevated serum triglycerides are a known risk factor for coronary heart disease (CHD) and long-term all-cause mortality [18, 19], suggesting that treatment with $3 \mathrm{D} \pm \mathrm{RBV}$ may lead to potential long-term beneficial cardiovascular outcomes.

\section{Metabolic EHMs}

Fasting blood glucose levels over $110 \mathrm{mg} / \mathrm{dl}$ have been associated with vascular complications [20]. Similarly, recurrence of cardiovascular events have been observed to increase as fasting plasma glucose levels rise above $90 \mathrm{mg} /$ $\mathrm{dl}$ and double with fasting plasma glucose levels of $110-115 \mathrm{mg} / \mathrm{dl}$ [21]. The American College of Endocrinology guidelines thus recommend a glycemic control target of $<110 \mathrm{mg} / \mathrm{dl}$ [35]. Results from our analysis showed that the overall mean decrease in serum glucose levels at 52 weeks post treatment with $3 \mathrm{D} \pm \mathrm{RBV}$ was $12.3 \mathrm{mg} / \mathrm{dl}$ overall, $4.3 \mathrm{mg} / \mathrm{dl}$ in patients with pre-diabetes and $34.2 \mathrm{mg} / \mathrm{dl}$ in patient with diabetes. Moreover, these patients were more likely to experience a decrease in serum glucose levels of $>20 \%$, which increases the likelihood of reducing glucose levels below $110 \mathrm{mg} / \mathrm{dl}$.

\section{Renal EHM}

The results of this analysis showed no significant impairment of renal function with $3 \mathrm{D} \pm \mathrm{RBV}$ treatment, consistent with previous studies of 3D clinical trial data [36]. Our study did identify a decrease in mean eGFR at week 52 for patients with CKD stage 1, which does not appear to be clinically meaningful and was not seen in patients with more advanced CKD at baseline. This finding might be attributed to differences in baseline characteristics between CKD groups, since a higher proportion of stage 1 patients had BMI $>30$ and HOMA-IR score $>3$ at baseline as compared to patients with lower eGFR levels as baseline. These factors have previously been associated with a decline in eGFR [37-39]. The overall decline in eGFR observed in 
treated patients during the post-treatment period is also consistent with the effect of aging as reported previously $[40,41]$. A meta-analysis of 35 cohorts of patients enrolled in a CKD prognosis consortium concluded that the adjusted HR of all-cause mortality and end-stage renal disease (ESRD) was largely unchanged in patients with an increase or decrease in eGFR of $10 \%$ or less relative to patients with stable eGFR, but was increased with eGFR declines greater than 10\%. Furthermore, patients with an increase in eGFR $>10 \%$ had a lower risk of progression to ESRD [20]. In the current analysis more than $40 \%$ of the $\mathrm{HCV}$-treated population who had a baseline eGFR $<60 \mathrm{ml} / \mathrm{min} / 1.73 \mathrm{~m}^{2}$ experienced an eGFR improvement of up to $20 \%$, suggesting that treatment with $3 \mathrm{D} \pm \mathrm{RBV}$ may reduce the risk of ESRD development and all-cause mortality in the long run.

Our findings should be interpreted within certain limitations. First, the parameters selected as surrogates for extrahepatic disease were chosen in a post hoc manner since they were routinely measured in clinical trials. If de novo trials were being conducted, different tests and biomarkers could improve the measurement of EHMs. For example, a fasting lipid panel would provide a more robust indication of cardiovascular risk than fasting triglycerides alone; serial HOMA-IR calculations would more precisely measure changes in glucose metabolism; serial urine collection would have allowed a more detailed description of the impact of treatment on renal disease. In addition, since the analysis was conducted on patients enrolled in clinical trials, it may have limited generalizability to the overall population. However, results seem consistent with prior literature assessing different patient populations. Furthermore, our analyses by baseline EHM severity did not distinguish between patients who did or did not achieve SVR. Nonetheless, it is likely that antiviral efficacy drives improvement in EHM biomarkers as the overall SVR rate in these trials exceeded 95\% and our regression models found a statistically significant association between viral load reduction and EHM biomarker improvements. This study might also suffer from unobservable bias where clinical variables (e.g., other comorbidities or concomitant medications) not collected in the database might influence the study results. To mitigate this issue, we leveraged double-blind trial data on patients randomly assigned to HCV treatment or placebo to assess the effect of treatment on EHM outcomes. Additionally, a real-world study did not find concomitant medications to be a significant predictor of EHM clinical outcomes in the presence of antiviral treatment [15]. In addition, we extrapolated the improvement observed in EHM biomarkers to clinical outcomes based on prior published literature. This may not be accurate and may warrant further research using real-world data with confirmed diagnosis of clinical outcomes. Finally, it should be noted that some of the patients included in the analysis did not receive an approved regimen as indicated in the current product label.

Nevertheless, this analysis contributes to the understanding of HCV treatment outcomes. It is one of the first to assess the impact of an oral IFN-free DAA regimen on EHM outcomes. It leverages a broad base of clinical trial data and included a comparison between treatment and placebo arms to evaluate the effect of DAA therapy on EHM outcomes.

\section{CONCLUSION}

In this post hoc analysis including large study populations, treatment with $3 \mathrm{D} \pm \mathrm{RBV}$ improved cardiovascular, metabolic and renal EHMs, especially in patients with elevated triglycerides, pre-diabetes/diabetes and CKD stage 2 and 3. CKD stage 4 and 5 patients had a stable eGFR during and post-treatment period. These positive effects of treatment on EHMs persisted at least 1 year post completion of treatment.

\section{ACKNOWLEDGMENTS}

The current work and the articles processing charges were supported by Abbvie Inc. Design and study conduct for the study was approved by AbbVie Inc. AbbVie Inc. participated in the interpretation of data and review and approval of the manuscript. All authors had full access to 
all of the data in this study and take complete responsibility for the integrity of the data and accuracy of the data analysis.

All named authors meet the International Committee of Medical Journal Editors (ICMJE) criteria for authorship for this manuscript, take responsibility for the integrity of the work as a whole and have given final approval to the version to be published.

Disclosures. Tram T. Tran received consulting, advisor/speaker fees and research grants from Gilead Sciences, Bristol-Myers Squibb and AbbVie. Darshan Mehta is financially supported for graduate research work by AbbVie as a part of a fellowship agreement between AbbVie and University of Southern California (USC). Eric Cohen is an employee of AbbVie Inc. and may own stocks and/or options of the company. Mariem Charafeddine is an employee of AbbVie Inc. and may own stocks and/or options of the company. Daniel Cohen is an employee of AbbVie Inc. and may own stocks and/or options of the company. Yanjun Bao is an employee of AbbVie Inc. and may own stocks and/or options of the company. Yuri Sanchez Gonzalez is an employee of AbbVie Inc. and may own stocks and/or options of the company.

Compliance with Ethics Guidelines. This analysis was conducted based on biomarker data collected in previously conducted studies and did not involve any new studies of human or animal subjects performed by any of the authors.

Data Availability. The underlying data during and/or analyzed during the current study are not publicly available as they are clinical trial data. However, we can release a summary of results (i.e., DOF packet) upon request.

Open Access. This article is distributed under the terms of the Creative Commons Attribution-NonCommercial 4.0 International License (http://creativecommons.org/licenses/ by-nc/4.0/), which permits any noncommercial use, distribution, and reproduction in any medium, provided you give appropriate credit to the original author(s) and the source, provide a link to the Creative Commons license, and indicate if changes were made.

\section{REFERENCES}

1. Centers for Disease Control and Prevention (CDC). Hepatitis C FAQs for Health Professionals. http:// www.cdc.gov/hepatitis/hcv/hcvfaq.htm\#section1. Accessed Sept 2016.

2. Chen SL, Morgan TR. The natural history of hepatitis $\mathrm{C}$ virus (HCV) infection. Int $\mathrm{J}$ Med Sci. 2006;3(2):47-52.

3. Cacoub P, Gragnani L, Comarmond C, Zignego AL. Extrahepatic manifestations of chronic hepatitis C virus infection. Dig Liver Dis. 2014;46:S165-73.

4. Cacoub P, Poynard T, Ghillani P, et al. Extrahepatic manifestations of chronic hepatitis C. MULTIVIRC Group. Multidepartment Virus C. Arthritis Rheum. 1999;42(10):2204-12.

5. Cacoub P, Comarmond C, Domont F, Savey L, Desbois AC, Saadoun D. Extrahepatic manifestations of chronic hepatitis $\mathrm{C}$ virus infection. Ther Adv Infect Dis. 2016;3(1):3-14.

6. Mahale P, Sturgis EM, Tweardy DJ, Ariza-Heredia EJ, Torres HA. Association between hepatitis $\mathrm{C}$ virus and head and neck cancers. J Natl Cancer Inst. 2016;108(8):djw035.

7. Voulgaris T, Sevastianos VA. Atherosclerosis as extrahepatic manifestation of chronic infection with hepatitis $\mathrm{C}$ virus. Hepat Res Treat. 2016;2016:8.

8. Gill K, Ghazinian H, Manch R, Gish R. Hepatitis C virus as a systemic disease: reaching beyond the liver. Hepatol Int. 2016;10(3):415-23.

9. Moorman AC, Tong X, Spradling PR, et al. Prevalence of renal impairment and associated conditions among HCV-infected persons in the Chronic Hepatitis Cohort Study (CHeCS). Dig Dis Sci. 2016;61(7):2087-93.

10. van der Meer AJ, Veldt BJ, Feld JJ, et al. Association between sustained virological response and all-cause mortality among patients with chronic hepatitis $\mathrm{C}$ andadvanced hepatic fibrosis. JAMA. 2012;308:2584-93. doi:10.1001/jama.2012.144878.

11. Morgan RL, Baack B, Smith BD, Yartel A, Pitasi M, Falck-Ytter Y. Eradication of hepatitis $C$ virus infection and the development of hepatocellular 
carcinoma: a meta-analysis of observational studies. Ann Intern Med. 2013;158:329-37.

12. Berenguer J, Alvarez-Pellicer J, Martin PM, et al. Sustained virological response to interferon plus ribavirin reduces liver-related complications and mortality in patients coinfected with human immunodeficiency virus and hepatitis $C$ virus. Hepatology. 2009;50:407-13.

13. Berenguer J, Rodriguez E, Miralles P, Von Wichmann MA, et al. Sustained virological response to interferon plus ribavirin reduces non-liver-related mortality in patients coinfected with HIV and Hepatitis C virus. Clin Infect Dis. 2012;55:728-36.

14. Hsu YC, Lin JT, Ho HJ, et al. Antiviral treatment for hepatitis $\mathrm{C}$ virus infection is associated with improved renal and cardiovascular outcomes in diabetic patients. Hepatology. 2014;59:1293-302.

15. Hsu YC, Ho HJ, Huang YT, et al. Association between antiviral treatment and extrahepatic outcomes in patients with hepatitis $\mathrm{C}$ virus infection. Gut. 2015;64:495-503.

16. Chattwal J. Direct acting antivirals for hepatitis c treatment: effectiveness versus cost-effectiveness. Future Virol. 2015;10(8):929-32.

17. http://hcvadvocate.org/hepatitis/factsheets_pdf/ Extrahepatic.pdf. Accessed May 2017

18. Emerging risk factor collaboration. Major lipids, apolipoproteins, and risk of vascular disease. JAMA. 2009;302(18):1993-2000.

19. Klempfner R, Erez A, Sagit BZ, et al. Elevated triglyceride level is independently associated with increased all-cause mortality in patients with established coronary heart disease twenty-two-year follow-up of the bezafibrate infarction prevention study and registry. Circ Cardiovasc Qual Outcomes. 2016;9:100-8. doi:10.1161/CIRCOUTCOMES.115. 002104.

20. The Expert Committee on the Diagnosis and Classification of Diabetes Mellitus. Report of the expert Committee on the diagnosis and classification of diabetes mellitus. Diabetes Care 2003;26(suppl 1):s5-s20. doi:10.2337/diacare.26.2007.S5

21. Goldberg RB, Mellies MJ, Sacks FM, et al. Cardiovascular events and their reduction with pravastatin in diabetic and glucose-intolerant myocardial infarction survivors with average cholesterol levels: subgroup analyses in the Cholesterol and Recurrent Events (CARE) trial. Circulation. 1998;98:2513-9.

22. Coresh J, Turin TC, Matsushita K, et al. Decline in estimated glomerular filtration rate and subsequent risk of end-stage renal disease and mortality. JAMA. 2014;311(24):2518-31.

23. Feld JJ, Kowdley KV, Coakley E, et al. Treatment of HCV with ABT-450/r-ombitasvir and dasabuvir with ribavirin. N Engl J Med. 2014;370:1594-603.

24. Zeuzem S, Jacobson IM, Baykal T, et al. Retreatment of HCV with ABT-450/r-ombitasvir and dasabuvir with ribavirin. N Engl J Med. 2014;370:1604-14.

25. Agarwal K, Gaeta GB, Lee SS, et al. Long-term clinical outcomes in HCV genotype 1-infected patients receiving ombitasvir/paritaprevir/ritonavir and dasabuvir \pm ribavirin: first interim safety and efficacy results from TOPAZ-I. In: AASLD 2016 Nov 11-15 Boston.

26. Reau N, Poodard F, Enejosa JV, et al. Preliminary safety and efficacy results from TOPAZ-II: a phase $3 \mathrm{~b}$ study evaluating long-term clinical outcomes in HCV genotype 1-infected patients receiving ombitasvir/paritaprevir/ritonavir and dasabuvir \pm ribavirin. In: AASLD 2015 Nov 13-17, San Francisco.

27. Pockros PJ, Reddy KR, Mantry PS, et al. Efficacy of direct-acting antiviral combination for patients with hepatitis $C$ virus genotype 1 infection and severe renal impairment or end-stage renal disease. Gastroenterology. 2016;150:1590-8.

28. Gane E, Sola R, Cohen E, et al. RUBY-II: efficacy and safety of a ribavirin-free ombitasvir/paritaprevir/ritonavir \pm dasabuvir regimen in patients with severe renal impairment or end-stage renal disease and $\mathrm{HCV}$ genotype $1 \mathrm{a}$ or 4 . In: Infection poster presented at AASLD 2016.

29. Albert PS. Longitudinal data analysis (repeated measures) in clinical trials. Stat Med. 1999;18:1707-32.

30. Executive Summary of The Third Report of The National Cholesterol Education Program (NCEP) Expert Panel on Detection, Evaluation, And Treatment of High Blood Cholesterol In Adults (Adult Treatment Panel III). JAMA. 2001;285:2486-97.

31. American Diabetes Association. Classification and diagnosis of diabetes. Diabetes Care. 2015;38(Suppl 1):S8-16. doi:10.2337/dc15-S005

32. Kidney Disease: Improving Global Outcomes (KDIGO) CKD Work Group. KDIGO 2012 Clinical Practice Guideline for the Evaluation and Management of Chronic Kidney Disease. Kidney Inter. Suppl. 2013;3:1-150.

33. Nahon P, Bourcier V, Layese R, et al. Eradication of hepatitis $C$ virus infection in patients with cirrhosis reduces risk of liver and non-liver complications. 
Gastroenterology. 2016;. doi:10.1053/j.gastro.2016. 09.009 .

34. Oh RC, Lanier BJ. Management of Hypertriglyceridemia. Am Fam Physician. 2007;75(1365-1371):1372.

35. American College of Endocrinology Consensus Statement on Guidelines for Glycemic Control. Endocr Pract. 2002;8(Suppl 1).

36. Bernstein D, Tran A, Kowdley et al. Predictors of improvement in glomerular filtration rate among patients treated with ombitasvir/paritaprevir/r and dasabuvir with or without ribavirin. In: Presented at AASLD 2016.

37. Wang Y, Chen X, Song Y, Caballero B, Cheskin LJ. Association between obesity and kidney disease: a systematic review and meta-analysis. Kidney Int. 2008;73(1):19-33 (Epub 2007 Oct 10).
38. Cheng HT, Huang JW, Chiang CK, Yen CJ, Hung $\mathrm{KY}$, $\mathrm{Wu} \mathrm{KD}$. Metabolic syndrome and insulin resistance as risk factors for development of chronic kidney disease and rapid decline in renal function in elderly. J Clin Endocrinol Metab. 2012;97(4):1268-76.

39. Chen S, Chen Y, Liu X, et al. Association of insulin resistance with chronic kidney disease in non-diabetic subjects with normal weight. PLoS One. 2013;8(9):e74058.

40. Cohen E, Nardi Y, Krause I, et al. A longitudinal assessment of the natural rate of decline in renal function with age. J Nephrol. 2014;27:635. doi:10. 1007/s40620-014-0077-9.

41. Baba $M$, Shimbo T, Horio $M$, et al. Longitudinal study of the decline in renal function in healthy subjects. PLoS One. 2015;10(6):e0129036. doi:10. 1371/journal.pone.0129036. 